\title{
A study of the validity of the efficiency transfer method to calculate the peak efficiency using $\gamma$-ray detectors at extremely large distances
}

\author{
Ahmed M. El-Khatib • Mohamed S. Badawi • \\ Mohamed A. Elzaher • Abouzeid A. Thabet
}

Received: 30 September 2013/ Accepted: 20 February 2014/Published online: 3 April 2014

(C) The Author(s) 2014. This article is published with open access at Springerlink.com

\begin{abstract}
The full-energy peak efficiency (FEPE) curves of the $\left(2^{\prime \prime} \times 2^{\prime \prime}\right.$ and $\left.3^{\prime \prime} \times 3^{\prime \prime}\right) \mathrm{NaI}(\mathrm{Tl})$ detectors were measured at seven different axial positions from their surfaces. The calibration process was done using radioactive point sources, which produce a wide energy range from 59.53 up to $1,408.01 \mathrm{keV}$. This work has been undertaken to explain the effects of source energy and sourcE-to-detector distance on the detector efficiency calculations. The study provides an empirical formula to calculate FEPE based on the efficiency transfer method for different detectors using the effective solid angle ratio at very large distances and for higher energies. A remarkable agreement between the measured and calculated efficiencies for the detectors at the sourcE-to-detector distances $<35 \mathrm{~cm}$ and above that slight difference was observed.
\end{abstract}

Keywords Scintillation detectors - Full-energy peak efficiency (FEPE) - Efficiency transfer method - Effective solid angle

A. M. El-Khatib · M. S. Badawi ( $₫)$

Physics Department, Faculty of Science, Alexandria University,

Alexandria 21511, Egypt

e-mail: ms241178@hotmail.com

A. M. El-Khatib

e-mail: elkhatib60@yahoo.com

M. A. Elzaher

Department of Basic and Applied Sciences, Faculty of Engineering, Arab Academy for Science, Technology and Maritime Transport, Alexandria, Egypt

A. A. Thabet

Department of Medical Equipment Technology, Pharos

University in Alexandria, Alexandria, Egypt

\section{Introduction}

The $\gamma$-ray scintillation detectors are forceful and low-cost spectrometer system (detectors and associated electronics), because spectra acquisition can be done at room temperature (no refrigeration); therefore, it can be used in various applications in the field under unfavorable weather conditions [1-3].

The full-energy peak efficiency (FEPE) was calculated before as described in [3-8]. Currently, it can also be calculated by using the efficiency transfer method empirically derived from an approximate calculation of the effective solid angle ratio. The effects of the distance and energy on the full-energy peak efficiency within the energy range of interest are explained in this work.

The efficiency transfer method is considered to be a trendy model for calculating the full-energy peak efficiencies (FEPEs) of a sample of interest on the basis of an experimental efficiency curve measured in the same detector, but with a calibrated sample of a different size, geometry, density and composition [9]. The procedure saves time and resources, since samplE-specific experimental calibration is avoided. It has long been established and useful especially in environmental measurements [10].

The method is based on the assumption that the detector efficiency at a reference position, $P_{\mathrm{o}}$, is the combination of the detector intrinsic efficiency, $\varepsilon_{i}(E)$, depending on the energy, $E$, and geometrical factors depending on both the photon energy and the measurement geometry [11]:

$\varepsilon\left(E, P_{\mathrm{o}}\right)=\varepsilon_{i}(E) \cdot \Omega_{\mathrm{eff}}\left(E, P_{\mathrm{o}}\right)$

where $\Omega_{\mathrm{eff}}\left(E, P_{\mathrm{o}}\right)$ is the effective solid angle between the source and the detector, which must include absorbing factors taking into account the attenuation effects of the 
materials between the source and the detector end cap. Thus, for any point source at position, $P$, the efficiency can be expressed as a function of the reference efficiency at the same energy, $E$, [11]:

$\varepsilon(E, P)=\varepsilon\left(E, P_{\mathrm{o}}\right) \frac{\Omega_{\mathrm{eff}}(E, P)}{\Omega_{\mathrm{eff}}\left(E, P_{\mathrm{o}}\right)}$

The conversion ratio $(R)$ of the effective solid angles is defined as:

$R=\frac{\Omega_{\mathrm{eff}}(E, P)}{\Omega_{\mathrm{eff}}\left(E, P_{\mathrm{o}}\right)}$

The effective solid angle subtended by the detector and the point source was calculated.

\section{Mathematical treatment}

Selim et al. using the spherical coordinate system derived a direct analytical elliptic integral method to calculate the detector efficiencies (total and full-energy peak) for any sourcE-detector configuration [12].

The pure solid angle subtended by the detector and the radioactive point source was defined as [13]:

$\Omega=\int_{\theta} \int_{\varphi} \sin \theta \mathrm{d} \varphi \mathrm{d} \theta$

Taking into account all the absorber materials between the source and detector, the effective solid angle was defined as:

$\Omega_{e f f}=\int_{\theta} \int_{\varphi} f_{\text {att }} \cdot \sin \theta d \varphi d \theta$

where $F_{\text {att }}$ factor determines the photon attenuation by all the absorber materials between the source and the detector and expressed as:

$f_{\text {att }}=e^{-\sum_{i} \mu_{i} \delta_{i}}$

In which, $\mu_{i}$, is the attenuation coefficient of the $i$ th absorber for a photon with energy $E_{\gamma}$, and $\delta_{\mathrm{i}}$ is the average photon path length through the $i$ th absorber.

For an arbitrarily positioned axial point source at height $\mathrm{h}$ from the detector of radius $R$, and side length, $L$, the polar, $\theta$, and the azimuthal, $\varphi$, angles at the point of entrance of the detector are defined as in [14].

The extreme values of the polar angles are:
Table 1 Detector setup parameters with acquisition electronics specifications for Detector D1 and Detector D2

\begin{tabular}{lll}
\hline Items & Detector (D1) & Detector (D2) \\
\hline Manufacturer & Canberra & Canberra \\
Serial number & 09L 654 & 09L 652 \\
Detector model & 802 & 802 \\
Type & Cylindrical & Cylindrical \\
Mounting & Vertical & Vertical \\
Resolution (FWHM) at $661 \mathrm{keV}$ & $7.5 \%$ & $8.5 \%$ \\
Cathode to anode voltage & $+900 \mathrm{~V} \mathrm{dc}$ & $+800 \mathrm{~V} \mathrm{dc}$ \\
Dynode to dynode & $+80 \mathrm{~V} \mathrm{dc}$ & $+80 \mathrm{~V} \mathrm{dc}$ \\
Cathode to dynode & $+150 \mathrm{~V} \mathrm{dc}$ & $+150 \mathrm{~V} \mathrm{dc}$ \\
Tube base & Model 2007 & Model 2007 \\
Shaping mode & Gaussian & Gaussian \\
Detector type & NaI(Tl) & NaI(Tl) \\
Crystal diameter $(\mathrm{mm})$ & 50.8 & 76.2 \\
Crystal length $(\mathrm{mm})$ & 50.8 & 76.2 \\
Top cover Thickness (mm) & Al $(0.5)$ & Al $(0.5)$ \\
Side cover thickness (mm) & Al $(0.5)$ & Al $(0.5)$ \\
Reflector-oxide (mm) & 2.5 & 2.5 \\
Weight (Kg) & 0.77 & 1.8 \\
Outer diameter (mm) & 57.2 & 80.9 \\
Outer length (mm) & 53.9 & 79.4 \\
Crystal volume $\left(\mathrm{cm}^{3}\right)$ & 102.96 & 347.49 \\
\hline
\end{tabular}

$\theta_{1}=\tan ^{-1}\left(\frac{R}{h+L}\right) \theta_{2}=\tan ^{-1}\left(\frac{R}{h}\right)$

In this situation, the lateral distance is equal to zero, and according to the present symmetry, the maximum azimuthal angles, $\varphi$, are equal to $2 \pi$.

Therefore, the effective solid angle of axial point source can be expressed as [12]:

$\Omega_{\mathrm{eff}}=\int_{0}^{\theta_{1}} \int_{0}^{2 \pi} f_{\mathrm{att}} \sin \theta d \varphi d \theta+\int_{\theta_{1}}^{\theta_{2}} \int_{0}^{2 \pi} f_{\mathrm{att}} \sin \theta d \varphi d \theta$

The previous integral is calculated numerically using the trapezoidal rule in a basic program.

\section{Experimental setup}

In this work, $\mathrm{NaI}(\mathrm{Tl})$ scintillation detectors $\left(2^{\prime \prime} \times 2^{\prime \prime} \&\right.$ $\left.3^{\prime \prime} \times 3^{\prime \prime}\right)$ were used, where the detector setup parameters with acquisition electronics specifications supported by the serial and model number are listed in Table 1.

The FEPE was measured using radioactive gamma-ray emitters (point sources) $\left[{ }^{241} \mathrm{Am},{ }^{133} \mathrm{Ba},{ }^{152} \mathrm{Eu},{ }^{137} \mathrm{Cs}\right.$ and ${ }^{60} \mathrm{Co}$, which was obtained from the Physikalisch- 
Table 2 PTB point source activities and their uncertainties

\begin{tabular}{llll}
\hline PTB-Nuclide & $\begin{array}{l}\text { Activity } \\
(\mathrm{KBq})\end{array}$ & $\begin{array}{l}\text { Reference Date } \\
\text { 00:00 Hr }\end{array}$ & $\begin{array}{l}\text { Uncertainty } \\
(\mathrm{KBq})\end{array}$ \\
\hline${ }^{241} \mathrm{Am}$ & 259.0 & 1.June 2009 & \pm 2.6 \\
${ }^{133} \mathrm{Ba}$ & 275.3 & & \pm 2.8 \\
${ }^{152} \mathrm{Eu}$ & 290.0 & & \pm 4.0 \\
${ }^{137} \mathrm{Cs}$ & 385.0 & & \pm 4.0 \\
${ }^{60} \mathrm{Co}$ & 212.1 & & \pm 1.5 \\
\hline
\end{tabular}

Table 3 Half-life, photon energies and photon emission probabilities per decay for all the radionuclides used in this work

\begin{tabular}{lrlr}
\hline PTB-nuclide & $\begin{array}{l}\text { Energy } \\
(\mathrm{keV})\end{array}$ & $\begin{array}{l}\text { Emission } \\
\text { probability } \%\end{array}$ & $\begin{array}{l}\text { Half-life } \\
\text { (Days) }\end{array}$ \\
\hline${ }^{241} \mathrm{Am}$ & 59.52 & 35.9 & 157861.05 \\
${ }^{133} \mathrm{Ba}$ & 80.99 & 34.1 & 3847.91 \\
${ }^{152} \mathrm{Eu}$ & 121.78 & 28.4 & 4943.29 \\
& 244.69 & 7.49 & \\
& 344.28 & 26.6 & \\
& 778.95 & 12.96 & 11004.98 \\
& 964.13 & 14.0 & 1925.31 \\
& 1408.01 & 20.87 & \\
${ }^{137} \mathrm{Cs}$ & 661.66 & 85.21 & \\
${ }^{60} \mathrm{Co}$ & 1173.23 & 99.9 & \\
& 1332.50 & 99.982 & \\
\hline
\end{tabular}

Technische Bundesanstalt (PTB) in Braunschweig and Berlin, Germany.

The certificates showing the sources' activities and their uncertainties are listed in Table 2. The data sheet states the values of half-life photon energies and photon emission probabilities per decay for all radionuclides used in the calibration process as listed in Table 3, which is available at the National Nuclear Data Center Web Page or on the IAEA website.

The homemade Plexiglass holder shown in Fig. 1 was used to measure these sources at seven different axial distances heading in the right direction from $20 \mathrm{~cm}$ till $50 \mathrm{~cm}$ with $5 \mathrm{~cm}$ steps from the detector surface. The holder was placed directly on the detector entrance window as an absorber. In most cases, the accompanying X-ray was soft enough to be absorbed completely before entering the detector. The sourcE-detector separations started from $20 \mathrm{~cm}$ to neglect the coincidence summing correction.

The spectrum was recorded as $P_{4} D 1$ where $P$ refers to the source type (point) measured at distance number (4) which equals $20 \mathrm{~cm}$ and $D 1$ refers to $\left(2^{\prime \prime} \times 2^{\prime \prime}\right)$ detector; so $P_{5} D 2$ means that the point source was measured at $25 \mathrm{~cm}$ from the $\left(3^{\prime \prime} \times 3^{\prime \prime}\right)$ detector, and so on.

The spectrum was acquired by winTMCA32 software which was made by ICx Technologies. It was analyzed by

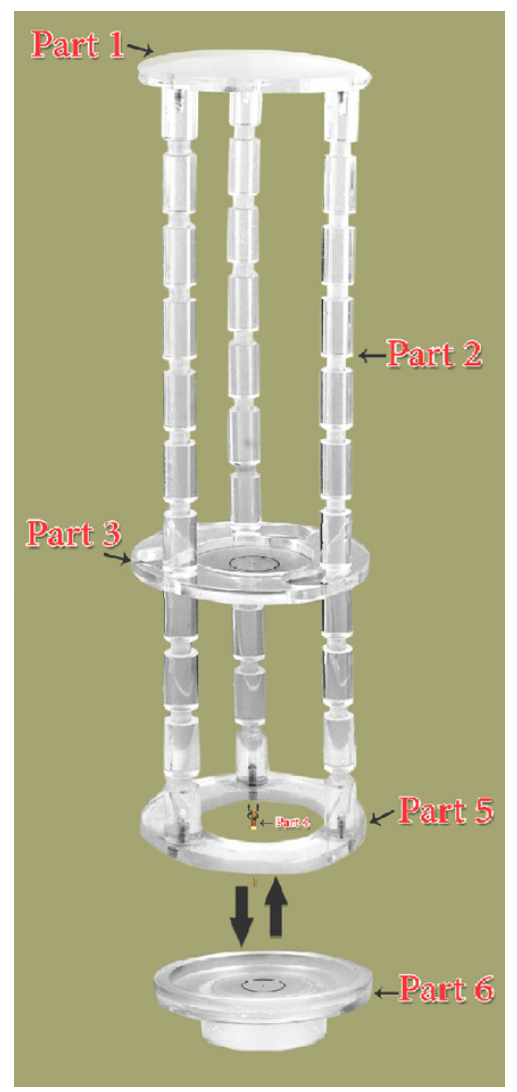

Fig. 1 Homemade Plexiglas holder

the Genie 2000 data acquisition and analysis software (Canberra Equipments) using the automatic peak search and the peak area calculations, along with changes in the peak fit using the interactive peak fit interface when necessary to reduce the residuals and errors in the peak area values. The live time, the run time and the start time for each spectrum were entered into the spreadsheets. These sheets were used to perform the calculations necessary to generate the experimental FEPE curves with their associated uncertainties.

\section{Experimental efficiencies}

The experimental efficiencies were determined by using the previously described standard sources. The experimental efficiency in energy, $E$, for a given set of measuring conditions can be computed by:

$\varepsilon(E)=\frac{N(E)}{T \cdot A_{S} \cdot P(E)} \prod C_{i}$

where $N(E)$ is the number of counts in the full-energy peak, $T$ is the measuring time (in seconds), $P(E)$ is the photon emission probability at energy $E, A_{\mathrm{S}}$, is the radionuclide 

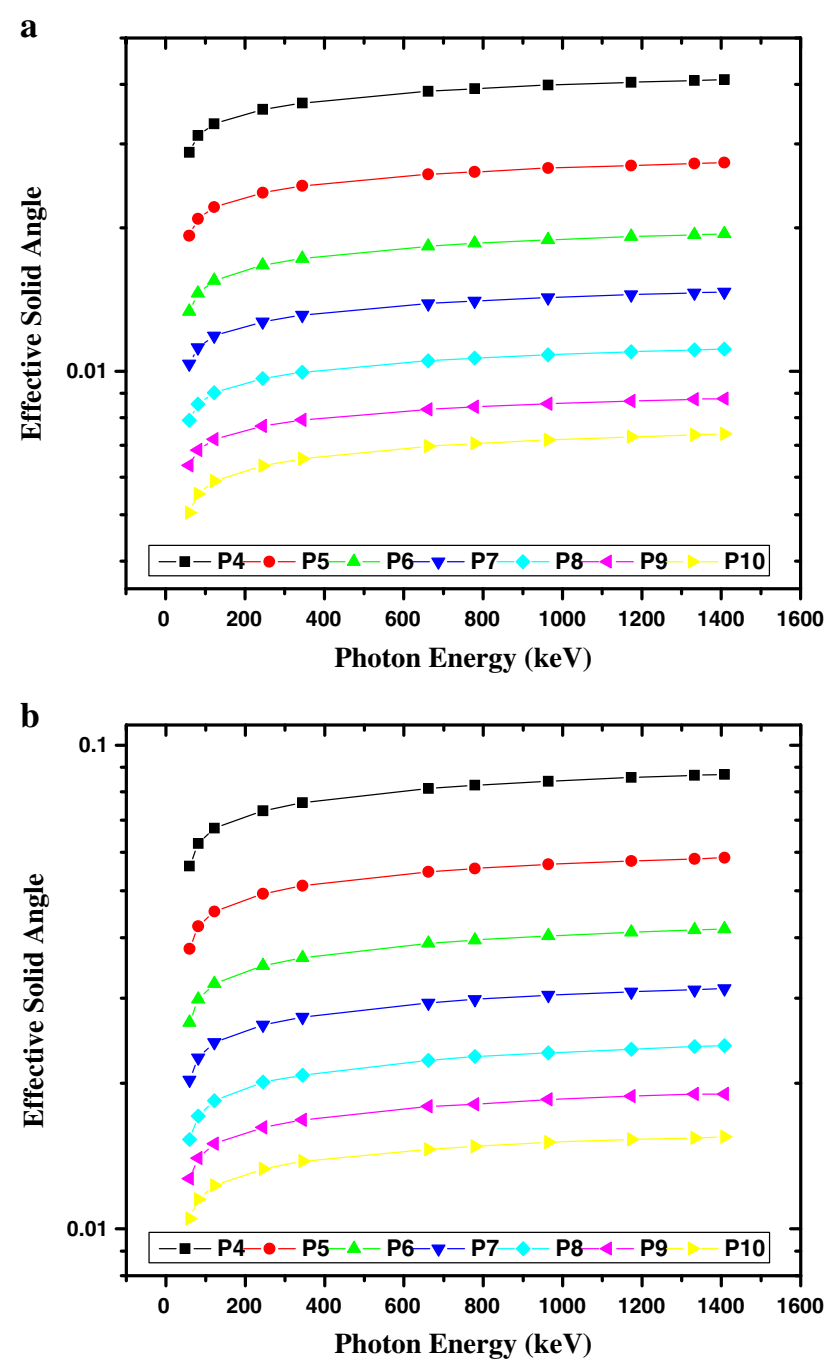

Fig. 2 Comparison between the effective solid angles from $P_{4}$ up to $P_{10}$ as a function of the photon energy

activity and $C_{i}$ are the correction factors due to dead time and radionuclide decay.

The measurements were done by using low activity sources so that the dead time was always $<3 \%$ and the corresponding factor was obtained by simply using ADC live time. The statistical uncertainties of the net peak areas were $<1.0 \%$ since the acquisition time was long enough to get the number of counts which was more than 10,000 counts. The decay correction, $C_{\mathrm{d}}$, for the calibration source from the reference time to the run time is given by:

$C_{d}=e^{\lambda \cdot \Delta T}$

where $\lambda$ is the decay constant and $\Delta T$ is the time interval over which the source decays corresponding to the run time.

The uncertainty in the experimental full-energy peak efficiency, $\sigma_{\varepsilon}$, is given by: $\sigma_{\varepsilon}=\varepsilon \cdot \sqrt{\left(\frac{\partial \varepsilon}{\partial A}\right)^{2} \cdot \sigma_{A}^{2}+\left(\frac{\partial \varepsilon}{\partial P}\right)^{2} \cdot \sigma_{P}^{2}+\left(\frac{\partial \varepsilon}{\partial N}\right)^{2} \cdot \sigma_{N}^{2}}$

where $\sigma_{\mathrm{A}}, \sigma_{\mathrm{P}}$ and $\sigma_{\mathrm{N}}$ are the uncertainties associated with the quantities, $A_{\mathrm{S}}, P(E)$, and $N(E)$, respectively, assuming that the only correction made is due to the source activity decay.

\section{Results and discussion}

The experimental study was carried out in the radiation physics laboratory (Prof. Y. S. Selim Laboratory, Department of Physics, Faculty of Science, Alexandria University, Egypt). This laboratory contains several NaI (Tl) scintillation detectors $\left(2^{\prime \prime} \times 2^{\prime \prime}\right.$ and $\left.3^{\prime \prime} \times 3^{\prime \prime}\right)$ used in this study. The detectors were calibrated by measuring the lowest activity point sources as previously described.

The effective solid angle as a function of the photon energy for both the scintillation detectors $\left(2^{\prime \prime} \times 2^{\prime \prime}\right.$ and $\left.3^{\prime \prime} \times 3^{\prime \prime}\right)$ is shown in Fig. $2 \mathrm{a}$, b, where it was small at height distance $P_{10}$ and large at low distance $P_{4}$. The effective solid angle below $121 \mathrm{keV}$ sharply increased at each position.

The experimental full-energy peak efficiency (FEPE) values of $P_{4} D 1$ and $P_{4} D 2$ are listed in Table 4 as a reference efficiency. The effective solid angle ratios for both detectors $(D 1$ and $D 2)$ produced due to conversion from $P_{4}$ as reference FEPE curve to $P_{5}$ up to $P_{10}$ FEPE curves are listed in Table (5). Figure $3 \mathrm{a}, \mathrm{b}$ shows that the effective solid angle ratio is approximately fixed for each position. The standard deviation for the effective solid angle ratio at each position was calculated and found to be $<0.003$ as listed in Table 5.

The calculated FEPE of $P_{5}$ up to $P_{10}$ was obtained by multiplying the reference efficiency at $P_{4}$ by the average value (conversion ratio) of the effective solid angle ratio for each position in Table 5 .

The percentage of error between the calculated and the measured efficiency is given by equation (11) and tabulated in Table 6:

$\Delta \%=\frac{\varepsilon_{\text {Cal }}-\varepsilon_{\text {meas }}}{\varepsilon_{\text {meas }}} \times 100$

where $\varepsilon_{\mathrm{cal}}$ and $\varepsilon_{\text {meas }}$ are the calculated and measured efficiencies, respectively.

The relation between the source height from the detector surface versus the average value of the effective solid angle ratio is shown in Fig. 4, where the effective solid angle ratio was obtained by using the conversion process from 
Table 4 Reference

experimental full-energy peak efficiency (FEPE) values for D1 and D2

\begin{tabular}{llllll}
\hline Nuclide & $\begin{array}{l}\text { Energy } \\
(\mathrm{keV})\end{array}$ & $\begin{array}{l}\text { Exp P4D1 } \\
\text { (Ref. Efficiency) }\end{array}$ & Uncertainty & $\begin{array}{l}\text { Exp P4D2 } \\
\text { (Ref. Efficiency) }\end{array}$ & Uncertainty \\
\hline Am-241 & 59.53 & $1.692 \mathrm{E}-03$ & $1.15 \mathrm{E}-05$ & $4.821 \mathrm{E}-03$ & $3.27 \mathrm{E}-05$ \\
Ba-133 & 80.99 & $1.868 \mathrm{E}-03$ & $1.36 \mathrm{E}-05$ & $5.273 \mathrm{E}-03$ & $3.85 \mathrm{E}-05$ \\
Eu-152 & 121.78 & $2.015 \mathrm{E}-03$ & $1.61 \mathrm{E}-05$ & $5.570 \mathrm{E}-03$ & $4.46 \mathrm{E}-05$ \\
Eu-152 & 244.69 & $1.575 \mathrm{E}-03$ & $1.15 \mathrm{E}-05$ & $4.523 \mathrm{E}-03$ & $3.31 \mathrm{E}-05$ \\
Eu-152 & 344.28 & $1.319 \mathrm{E}-03$ & $9.99 \mathrm{E}-06$ & $3.755 \mathrm{E}-03$ & $2.84 \mathrm{E}-05$ \\
Cs-137 & 661.66 & $7.410 \mathrm{E}-04$ & $4.13 \mathrm{E}-06$ & $2.097 \mathrm{E}-03$ & $1.17 \mathrm{E}-05$ \\
Eu-152 & 778.95 & $6.013 \mathrm{E}-04$ & $4.39 \mathrm{E}-06$ & $1.760 \mathrm{E}-03$ & $1.28 \mathrm{E}-05$ \\
Eu-152 & 964.13 & $4.730 \mathrm{E}-04$ & $3.53 \mathrm{E}-06$ & $1.376 \mathrm{E}-03$ & $1.03 \mathrm{E}-05$ \\
Co-60 & 1173.23 & $3.915 \mathrm{E}-04$ & $1.67 \mathrm{E}-06$ & $1.110 \mathrm{E}-03$ & $4.75 \mathrm{E}-06$ \\
Co-60 & 1332.50 & $3.389 \mathrm{E}-04$ & $1.45 \mathrm{E}-06$ & $9.870 \mathrm{E}-04$ & $4.22 \mathrm{E}-06$ \\
Eu-152 & 1408.01 & $3.109 \mathrm{E}-04$ & $2.23 \mathrm{E}-06$ & $9.467 \mathrm{E}-04$ & $6.78 \mathrm{E}-06$ \\
\hline
\end{tabular}

Table 5 The effective solid angle ratio for conversion from the reference curve of FEPE $P_{4}$ to $P_{5}$ up to $P_{10}$

\begin{tabular}{|c|c|c|c|c|c|c|c|c|}
\hline Nuclide & Energy & $\frac{\Omega_{\mathbf{p} 4}}{\Omega_{\mathbf{p} 4}}$ & $\frac{\Omega_{\mathbf{p} 5}}{\Omega_{\mathbf{p} 4}}$ & $\frac{\Omega_{\mathrm{p} 6}}{\boldsymbol{\Omega}_{\mathbf{p} 4}}$ & $\frac{\Omega_{\mathrm{p} 7}}{\Omega_{\mathrm{p} 4}}$ & $\frac{\Omega_{\mathrm{p} 8}}{\boldsymbol{\Omega}_{\mathrm{p} 4}}$ & $\frac{\boldsymbol{\Omega}_{\mathrm{p} 9}}{\boldsymbol{\Omega}_{\mathbf{p} 4}}$ & $\frac{\Omega_{\mathrm{p} 10}}{\boldsymbol{\Omega}_{\mathrm{p} 4}}$ \\
\hline \multicolumn{9}{|c|}{ Detector (D1) effective solid angle ratio } \\
\hline Am-241 & 59.53 & 1 & $6.695 \mathrm{E}-01$ & $4.639 \mathrm{E}-01$ & $3.602 \mathrm{E}-01$ & $2.741 \mathrm{E}-01$ & $2.206 \mathrm{E}-01$ & $1.755 \mathrm{E}-01$ \\
\hline Ba-133 & 80.99 & 1 & $6.695 \mathrm{E}-01$ & $4.672 \mathrm{E}-01$ & $3.595 \mathrm{E}-01$ & $2.735 \mathrm{E}-01$ & $2.190 \mathrm{E}-01$ & $1.771 \mathrm{E}-01$ \\
\hline Eu-152 & 121.78 & 1 & $6.694 \mathrm{E}-01$ & $4.692 \mathrm{E}-01$ & $3.592 \mathrm{E}-01$ & $2.731 \mathrm{E}-01$ & $2.179 \mathrm{E}-01$ & $1.780 \mathrm{E}-01$ \\
\hline Eu-152 & 244.69 & 1 & $6.694 \mathrm{E}-01$ & $4.711 \mathrm{E}-01$ & $3.589 \mathrm{E}-01$ & $2.728 \mathrm{E}-01$ & $2.167 \mathrm{E}-01$ & $1.789 \mathrm{E}-01$ \\
\hline Eu-152 & 344.28 & 1 & $6.693 \mathrm{E}-01$ & $4.719 \mathrm{E}-01$ & $3.588 \mathrm{E}-01$ & $2.726 \mathrm{E}-01$ & $2.161 \mathrm{E}-01$ & $1.793 \mathrm{E}-01$ \\
\hline Cs-137 & 661.66 & 1 & $6.693 \mathrm{E}-01$ & $4.733 \mathrm{E}-01$ & $3.587 \mathrm{E}-01$ & $2.723 \mathrm{E}-01$ & $2.152 \mathrm{E}-01$ & $1.800 \mathrm{E}-01$ \\
\hline Eu-152 & 778.95 & 1 & $6.693 \mathrm{E}-01$ & $4.736 \mathrm{E}-01$ & $3.586 \mathrm{E}-01$ & $2.722 \mathrm{E}-01$ & $2.149 \mathrm{E}-01$ & $1.801 \mathrm{E}-01$ \\
\hline Eu-152 & 964.13 & 1 & $6.693 \mathrm{E}-01$ & $4.740 \mathrm{E}-01$ & $3.586 \mathrm{E}-01$ & $2.721 \mathrm{E}-01$ & $2.147 \mathrm{E}-01$ & $1.803 \mathrm{E}-01$ \\
\hline Co-60 & 1173.23 & 1 & $6.692 \mathrm{E}-01$ & $4.743 \mathrm{E}-01$ & $3.585 \mathrm{E}-01$ & $2.721 \mathrm{E}-01$ & $2.144 \mathrm{E}-01$ & $1.805 \mathrm{E}-01$ \\
\hline Co-60 & 1332.50 & 1 & $6.692 \mathrm{E}-01$ & $4.746 \mathrm{E}-01$ & $3.585 \mathrm{E}-01$ & $2.720 \mathrm{E}-01$ & $2.143 \mathrm{E}-01$ & $1.806 \mathrm{E}-01$ \\
\hline Eu-152 & 1408.01 & 1 & $6.692 \mathrm{E}-01$ & $4.747 \mathrm{E}-01$ & $3.585 \mathrm{E}-01$ & $2.720 \mathrm{E}-01$ & $2.142 \mathrm{E}-01$ & $1.807 \mathrm{E}-01$ \\
\hline \multicolumn{2}{|c|}{ Mean (average) } & 1 & $6.693 \mathrm{E}-01$ & $4.716 \mathrm{E}-01$ & $3.589 \mathrm{E}-01$ & $2.726 \mathrm{E}-01$ & $2.162 \mathrm{E}-01$ & $1.792 \mathrm{E}-01$ \\
\hline \multicolumn{2}{|c|}{ Standard deviation } & 0 & $1.000 \mathrm{E}-04$ & $3.500 \mathrm{E}-03$ & $5.200 \mathrm{E}-04$ & $6.900 \mathrm{E}-04$ & $2.150 \mathrm{E}-03$ & $1.670 \mathrm{E}-03$ \\
\hline \multicolumn{9}{|c|}{ Detector (D2) effective solid angle ratio } \\
\hline Am-241 & 59.53 & 1 & $6.746 \mathrm{E}-01$ & $4.759 \mathrm{E}-01$ & $3.607 \mathrm{E}-01$ & $2.725 \mathrm{E}-01$ & $2.253 \mathrm{E}-01$ & $1.863 \mathrm{E}-01$ \\
\hline Ba-133 & 80.99 & 1 & $6.741 \mathrm{E}-01$ & $4.767 \mathrm{E}-01$ & $3.608 \mathrm{E}-01$ & $2.731 \mathrm{E}-01$ & $2.237 \mathrm{E}-01$ & $1.846 \mathrm{E}-01$ \\
\hline Eu-152 & 121.78 & 1 & $6.738 \mathrm{E}-01$ & $4.772 \mathrm{E}-01$ & $3.608 \mathrm{E}-01$ & $2.735 \mathrm{E}-01$ & $2.226 \mathrm{E}-01$ & $1.833 \mathrm{E}-01$ \\
\hline Eu-152 & 244.69 & 1 & $6.734 \mathrm{E}-01$ & $4.778 \mathrm{E}-01$ & $3.608 \mathrm{E}-01$ & $2.739 \mathrm{E}-01$ & $2.214 \mathrm{E}-01$ & $1.817 \mathrm{E}-01$ \\
\hline Eu-152 & 344.28 & 1 & $6.733 \mathrm{E}-01$ & $4.781 \mathrm{E}-01$ & $3.608 \mathrm{E}-01$ & $2.740 \mathrm{E}-01$ & $2.209 \mathrm{E}-01$ & $1.810 \mathrm{E}-01$ \\
\hline Cs-137 & 661.66 & 1 & $6.730 \mathrm{E}-01$ & $4.785 \mathrm{E}-01$ & $3.607 \mathrm{E}-01$ & $2.743 \mathrm{E}-01$ & $2.199 \mathrm{E}-01$ & $1.796 \mathrm{E}-01$ \\
\hline Eu-152 & 778.95 & 1 & $6.729 \mathrm{E}-01$ & $4.786 \mathrm{E}-01$ & $3.607 \mathrm{E}-01$ & $2.744 \mathrm{E}-01$ & $2.196 \mathrm{E}-01$ & $1.793 \mathrm{E}-01$ \\
\hline Eu-152 & 964.13 & 1 & $6.728 \mathrm{E}-01$ & $4.788 \mathrm{E}-01$ & $3.607 \mathrm{E}-01$ & $2.745 \mathrm{E}-01$ & $2.193 \mathrm{E}-01$ & $1.790 \mathrm{E}-01$ \\
\hline Co-60 & 1173.23 & 1 & $6.727 \mathrm{E}-01$ & $4.789 \mathrm{E}-01$ & $3.607 \mathrm{E}-01$ & $2.745 \mathrm{E}-01$ & $2.191 \mathrm{E}-01$ & $1.786 \mathrm{E}-01$ \\
\hline Co-60 & 1332.50 & 1 & $6.727 \mathrm{E}-01$ & $4.790 \mathrm{E}-01$ & $3.607 \mathrm{E}-01$ & $2.746 \mathrm{E}-01$ & $2.190 \mathrm{E}-01$ & $1.784 \mathrm{E}-01$ \\
\hline Eu-152 & 1408.01 & 1 & $6.726 \mathrm{E}-01$ & $4.790 \mathrm{E}-01$ & $3.607 \mathrm{E}-01$ & $2.746 \mathrm{E}-01$ & $2.189 \mathrm{E}-01$ & $1.784 \mathrm{E}-01$ \\
\hline \multicolumn{2}{|c|}{ Mean (average) } & 1 & $6.733 \mathrm{E}-01$ & $4.780 \mathrm{E}-01$ & $3.607 \mathrm{E}-01$ & $2.740 \mathrm{E}-01$ & $2.209 \mathrm{E}-01$ & $1.809 \mathrm{E}-01$ \\
\hline \multicolumn{2}{|c|}{ Standard deviation } & 0 & $6.600 \mathrm{E}-04$ & $1.040 \mathrm{E}-03$ & $5.000 \mathrm{E}-05$ & $6.900 \mathrm{E}-04$ & $2.160 \mathrm{E}-03$ & $2.710 \mathrm{E}-03$ \\
\hline
\end{tabular}

position $P_{4}$ for both the detectors. The detector efficiency especial effects only by the reference efficiency value as it increases, as the detector efficiency increase. The fitting equation for this curve was obtained from the Origin 8 program and found to be in exponential decay as the following: 

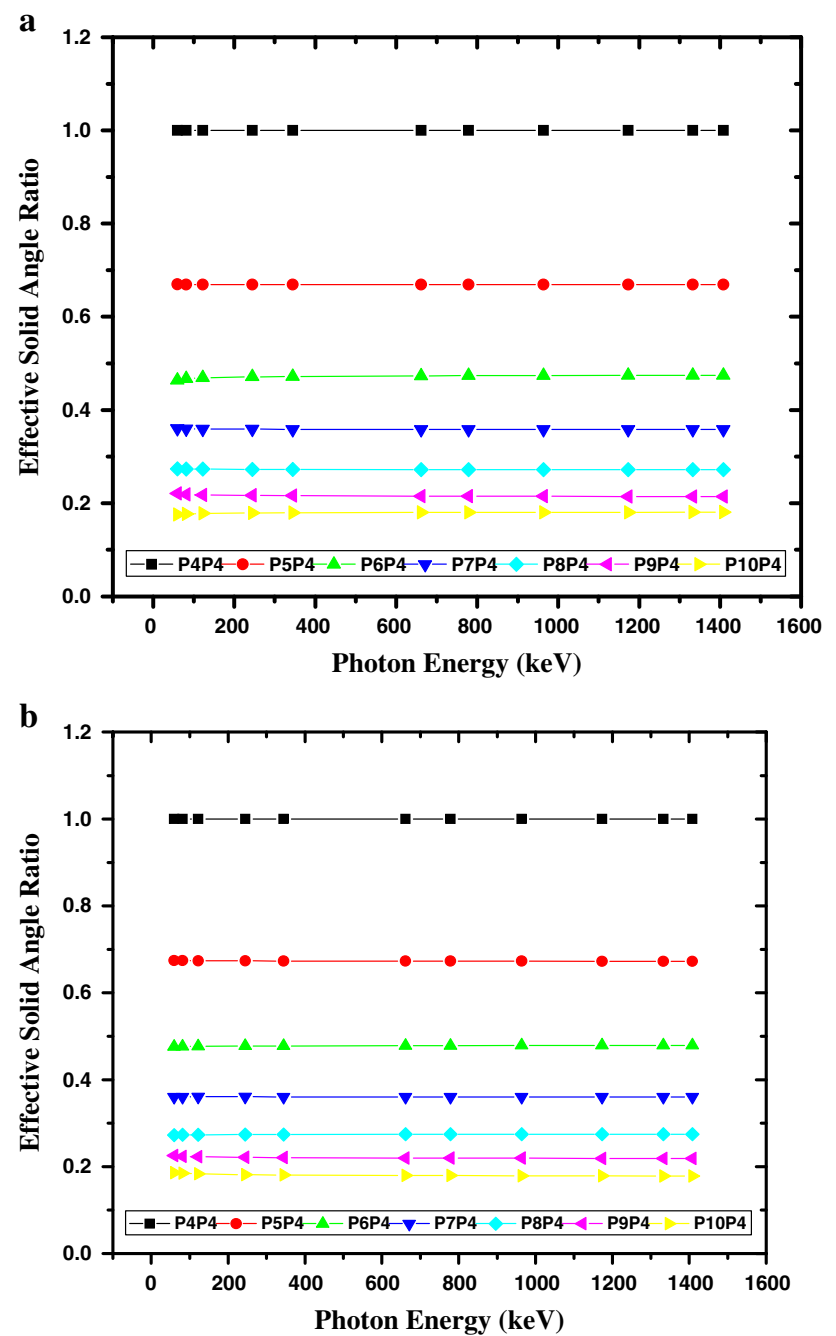

Fig. 3 The effective solid angle ratio for conversion from $P_{4}$ as the reference curve of FEPE to $P_{5}$ up to $P_{10}$ as a function of the photon energy

$R_{x}=R_{o}+A e^{-\left(\frac{x}{t}\right)}$

where $R_{x}$ is the conversion ratio from $P_{4}$ to $P_{x}$, and $\mathrm{x}$ is the axial source height position from the detector surface in $\mathrm{cm}$. The parameters of this equation are shown in Table 7.

This equation is valid to determine the effective solid angle ratio values for different axial distances from the detector surface, which led to determine FEPE theoretically simply, without the need of experimental work at any distance, through the region of interest in this study.

Therefore, Eq. (2) is:

$\varepsilon(E, P)=\varepsilon\left(E, P_{4}\right) R_{x}$

There is a relative difference between the measured and the calculated value jumps from one percent to several percents in Table 6 , which indicates some sort of failure of the efficiency transfer methodology in general at very large distances and for higher energies which can be explained in some points as follows.

- The efficiency increases with increasing the detector's volume and at lower distances from the detector surface, but the crystal is not long enough to have a reasonable efficiency for the highest energy gamma rays. This is due to the change in solid angle and the interaction of gamma ray with the detector's material beside the long distance from the detector end cap. These phenomena are related to the fact that the gamma ray intensity emanating from a source falls off with a distance according to the inverse square law. In addition, low efficiency values for point source are measured at $20 \mathrm{~cm}$ and more distance away from the detector. At the same time, there was also a strong increase in the efficiency value of the detector, experimentally observed for energy $<100 \mathrm{keV}$ [which is related to the decrease in the attenuation of the end-cap material, aluminum $(2.69 \mathrm{~g} / \mathrm{cm} 3)]$ and this effect is almost negligible for a very long distance from the detector.

- The contribution to the full-energy peak from the Compton process is large for larger crystals and at lower distances from the detector surface, where the photon path length of the crystal is large and it is almost negligible for the small crystal and at very long distance from the detector, while the full-energy peak feature results from the gamma-ray that has a photoelectric interaction that produces an electron, which deposits its entire energy in the detector. This result increases the overall efficiency.

- The efficiency of the detectors is higher at low source energies (absorption coefficient is very high) and decreases as the energy increases (fall off in the absorption coefficient), because the photoelectricity is dominant below $100 \mathrm{keV}$, which means in other words that it is higher for the bigger detector or low source distance than the smaller one or higher source distance. It is higher for lower source energy than higher source energy because of the dominance of the photoelectricity at lower source energies.

- There is an accuracy problem in measuring the height by increasing the distances between the source and the detector. Another problem is the finE-tuning adjustment problem with the detector's parameters and the geometry of the instrument used.

\section{Conclusion}

This work leads to a simple method to evaluate the fullenergy peak efficiency (FEPE) based on the efficiency 


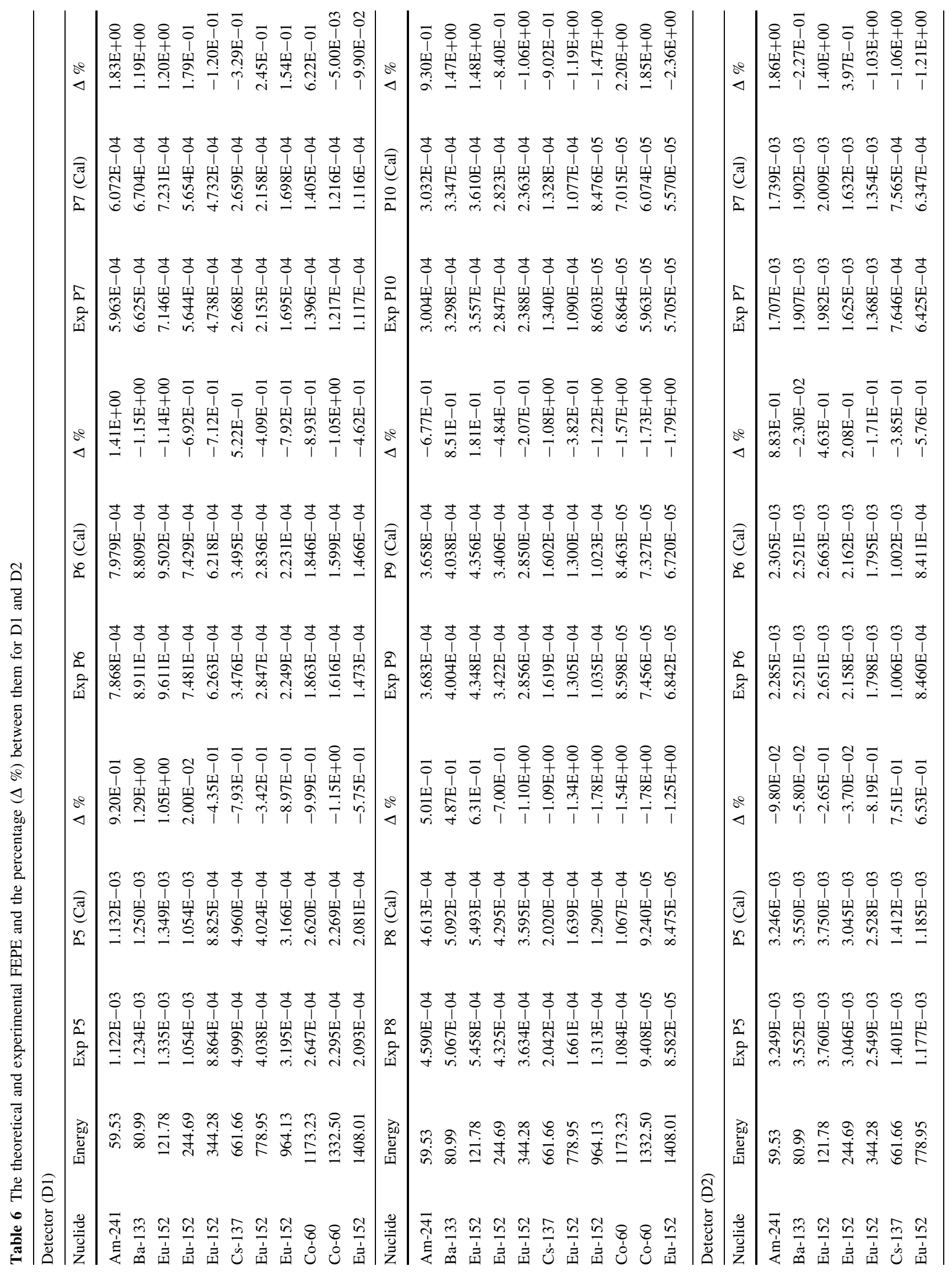




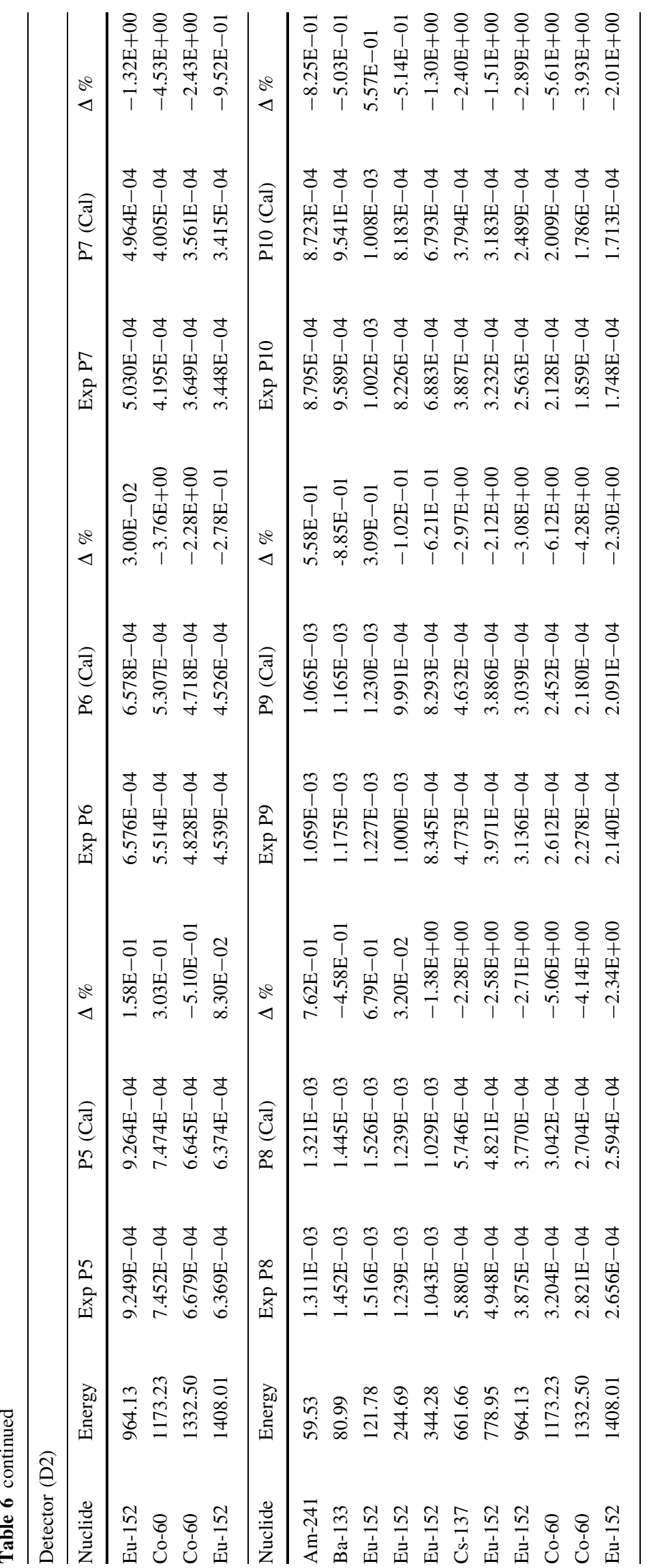




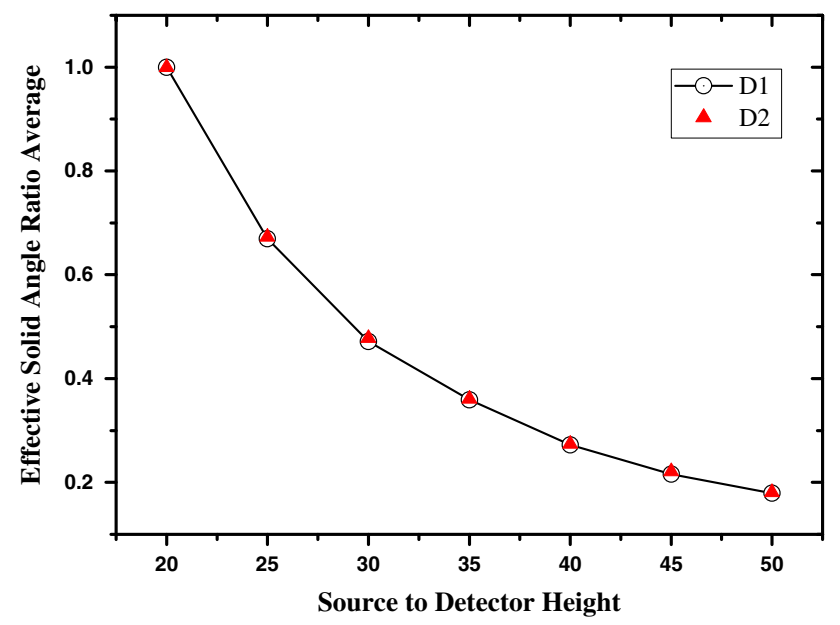

Fig. 4 The average value of the effective solid angle ratio as a function of the source height from the detector surface

Table 7 Parameters of the fitting equation

\begin{tabular}{lll}
\hline Parameter & Value & Error \\
\hline$R_{\mathrm{O}}$ & 0.12995 & 0.01008 \\
$A$ & 5.3767 & 0.29335 \\
$t$ & 10.95715 & 0.36099 \\
$\mathrm{Chi}^{2}$ & $5.47991 \mathrm{E}-5$ & \\
$R^{2}$ & 0.99958 & \\
\hline
\end{tabular}

transfer method over a wide energy range, which deals with the detector in the case of an axial isotropic point source. The method represents an empirical formula based on the effective solid angle ratio. The obtained data show that the discrepancy between the experimental and the calculated values of FEPE was $<3 \%$ at distances $<35 \mathrm{~cm}$ and about $7 \%$ at greater distance from the detector surface. Therefore, the present approach shows a great possibility for calibrating the detectors through the determination of a full-energy peak efficiency curve to avoid consuming time except at very large distances and for higher energies where the discrepancies increase due to the change in solid angle.
Acknowledgments The authors would like to express their sincere thanks to Prof. Dr. Mahmoud. I. Abbas, Faculty of Science, Alexandria University, for the very valuable professional guidance in the area of radiation physics and for his fruitful scientific collaborations on this topic. Also, Dr. Mohamed S. Badawi would like to specially thank the Physikalisch-Technische Bundesanstalt (PTB) in Braunschweig, Berlin, Germany, for fruitful help in supporting the sources.

Open Access This article is distributed under the terms of the Creative Commons Attribution License which permits any use, distribution, and reproduction in any medium, provided the original author(s) and the source are credited.

\section{References}

1. Salgado, C.M., Brandão, L.E.B., Schirru, R., Pereira, C.M.N.A., Conti, C.C.: Prog. Nucl. Energy 59, 19-25 (2012)

2. El-Khatib, A.M., Badawi, M. S., Elzaher, M.A., Thabet, A.A.: Proceeding of "XI Radiation Physics and Protection Conference", (25-28 November 2012) Nasr City Cairo-Egypt

3. Elzaher, M.A., Badawi, M.S., El-Khatib, A.M., Thabet, A.A.: World J. Nucl. Sci. Technol. 2, 65-72 (2012)

4. El-Khatib, A.M., Badawi, M.S., Mohamed, A., Elzaher, A., Thabet, A.: J. Adv. Res. Phys. 3(2), 021204 (2012)

5. Badawi, M.S., Gouda, M.M., Nafee, S.S., El-Khatib, A.M., ElMallah, E.A.: Nucl. Instrum. Methods Phys. Res. A 696, 164-170 (2012)

6. Badawi, M.S., Gouda, M.M., Nafee, S.S., El-Khatib, A.M., ElMallah, E.A.: Appl. Radiat. Isot. 70(12), 2661-2668 (2012)

7. Hamzawy, A.: Nucl. Instrum. Methods Phys. Res. A 624, 125-129 (2010)

8. Badawi, Elzaher, M.A., Thabet, A.A., El-Khatib, A.M.: Appl. Radiat. Isot. 74, 46-49 (2013)

9. Vidmar, T., Celik, N., CornejoDiaz, N., Dlabac, A., et al.: Appl. Radiat. Isot. 68, 355-359 (2010)

10. Gilmore, G.R.: Practical Gamma-ray Spectrometry, 2nd edn. Wiley, New York (2008)

11. Le'py, M.-C., Brun, P., Collin, C., Plagnard, J.: Appl. Radiat. Isot. 64, 1340-1345 (2006)

12. Badawi, M.S.: Comparative Study of the Efficiency of Gammarays Measured by Compact-and Well TypE-Cylindrical Detectors. PhD. Thesis, Faculty of Science Alexandria University Egypt 2010

13. Pibida, L., Nafee, S.S., Unterweger, M., Hammond, M.M., Karam, L., Abbas, M.I.: Appl. Radiat. Isot. 65, 225-233 (2007)

14. El-Khatib, A.M., Gouda, M.M., Badawi, M.S., Nafee, S.S., ElMallah Radiat, E.A.: Protect. Dosim. 1-9 (2013). doi:10.1093/ $\mathrm{rpd} / \mathrm{nct} 048$ 